\title{
Chemical changes that predispose smoked Cheddar cheese to calcium lactate crystallization
}

\author{
P. Rajbhandari, J. Patel, E. Valentine, and P. S. Kindstedt ${ }^{1}$ \\ Department of Nutrition and Food Sciences, University of Vermont, Burlington 05405-0086
}

\begin{abstract}
We have observed a high incidence of calcium lactate surface crystals on naturally smoked Cheddar cheese in the retail marketplace. The objective of this study was to identify chemical changes that may occur during natural smoking that render Cheddar cheese more susceptible to calcium lactate crystal formation. Nine random-weight (approximately $300 \mathrm{~g}$ ) retail-packaged samples of smoked Cheddar cheese were obtained from a commercial manufacturer immediately after the samples were smoked for about $6 \mathrm{~h}$ at $20^{\circ} \mathrm{C}$ in a commercial smokehouse. Three similarly sized samples that originated from the same $19.1-\mathrm{kg}$ block of cheese and that were not smoked were also obtained. Within $2 \mathrm{~d}$ after smoking, 3 smoked and 3 control (not smoked) samples were sectioned into 5 subsamples at different depths representing 0 to 2,2 to 4,4 to 6,6 to 8 , and 8 to $10 \mathrm{~mm}$ from the cheese surface. Six additional smoked cheese samples were similarly sectioned at $4 \mathrm{wk}$ and again at $10 \mathrm{wk}$ of storage at $5^{\circ} \mathrm{C}$. Sample sections were analyzed for moisture, $\mathrm{L}(+)$ and $\mathrm{D}(-)$ lactate, $\mathrm{pH}$, and water-soluble calcium. The effects of treatment (smoked, control), depth from cheese surface, and their interactions were analyzed by ANOVA according to a repeated measures design with 2 within-subject variables. Smoked samples contained signficantly lower moisture and lower $\mathrm{pH}$, and higher total lactate-inmoisture (TLIM) and water-soluble calcium-in-moisture (WSCIM) than control cheeses. Smoked samples also contained significant gradients of moisture, $\mathrm{pH}$, TLIM, and WSCIM, with lower moisture and $\mathrm{pH}$, and higher TLIM and WSCIM, occurring at the cheese surface. Gradients of moisture were still present in smoked samples at 4 and $10 \mathrm{wk}$ of storage. In contrast, the $\mathrm{pH}$, TLIM, and WSCIM equilibrated and showed no gradients at 4 and $10 \mathrm{wk}$. The results indicate that calcium and lactate in the serum phase of the cheese were elevated because of smoking, especially at the cheese surface immediately after smoking treatment,
\end{abstract}

Received February 23, 2009.

Accepted April 2, 2009.

${ }^{1}$ Corresponding author: paul.kindstedt@uvm.edu which presumably predisposes the smoked cheeses to increased susceptibility to calcium lactate surface crystallization.

Key words: Cheddar cheese, calcium lactate, crystal

\section{INTRODUCTION}

Naturally smoked cheeses are considered specialty cheeses in the United States and represent an important value-added niche category (US Dairy Export Council, 2007). Smoking is employed for some artisanal cheeses to mimic the smoky character of traditional cheeses that were produced with open wood fires in cheesemaking huts in former times (Bosset et al., 1999). Smoking is also one of the oldest forms of food preservation and was used for this purpose in the making of some traditional cheeses. In the United States today, natural vaporous smoking is used primarily to enhance the flavor, color, and marketing image of cheese, and the practice appears to be growing in popularity, despite concerns that have been raised about the absorption of potential carcinogens by the cheese during exposure to vaporous smoke (Riha et al., 1992; Anastasio et al., 2004; Guillén and Sopelana, 2004; Guillén et al., 2007; Suchanová et al., 2008). Cheddar cheese is among the most popular of the smoked cheese varieties in the United States, and the effects of smoking on the color, flavor, and aging characteristics of Cheddar cheese have been investigated (Riha and Wendorff, 1993; ShakeelUr-Rehman et al., 2003).

The composition of woodsmoke is very complex and is known to contain acids, carbonyls, alcohols, phenolics, and other neutral compounds (Lustre and Issenberg, 1969). Many of the fat-soluble compounds present in wood smoke are absorbed into the cheese surface during natural smoking (Guillén and Sopelana, 2004), and presumably the same is true for water-soluble components such as acids, although this has not been investigated in cheese. The brown color that develops at the surface of protein-based foods during smoking is primarily caused by nonenzymatic browning reactions involving amino groups on food proteins and carbonyl compounds in the smoke (Gilbert and Knowles, 1975; Ruiter, 1979). The darkened surface of smoked Cheddar cheese contrasts 
sharply with white crystals of Ca lactate that sometimes form on the surface of Cheddar during ripening, rendering the crystals remarkably bright and easy to distinguish (Rajbhandari and Kindstedt, 2005b). Thus, Ca lactate crystallization has a much greater visual impact when it occurs at the surface of smoked Cheddar cheese than on unsmoked or uncolored cheese. For some artisanal cheeses, Ca lactate crystals may be considered desirable, but most often they are considered a defect that Cheddar cheesemakers seek to avoid (Swearingen et al., 2004).

We have reported previously (Rajbhandari and Kindstedt, 2005a) that some commercially produced smoked Cheddar cheeses in local retail markets appear to experience a high incidence of Ca lactate crystallization. We have also observed a high incidence of Ca lactate crystallization in smoked Gouda cheeses (unpublished data). In an earlier study, we reported that retail samples of smoked Cheddar cheese contained significant gradients of moisture, which were presumed to be the consequence of surface dehydration during smoking (Rajbhandari and Kindstedt, 2005a). Surface dehydration of cheese may occur during natural smoking (Washam et al., 1985), although this is not always the case depending on the method of smoke exposure (Shakeel-Ur-Rehman et al., 2003). It seems possible that dehydration coupled with other possible chemical changes caused by absorption of smoke components may predispose smoked Cheddar cheeses to enhanced Ca lactate crystallization. The objective of the present study was to investigate chemical changes that occur in Cheddar cheese as a result of natural smoking under commercial conditions that may elevate the potential for Ca lactate crystallization.

\section{MATERIALS AND METHODS}

Cheese samples for this study were provided by a commercial manufacturer. Cheeses were produced by a milled curd procedure using an automated production line that included enclosed vats $(22,727-\mathrm{kg}$ capacity) for coagulating the milk and cooking the curd; an enclosed conveyor series for continuous dewheying, cheddaring, and milling; enclosed mechanical metering of dry salt and automated stirring of salted curd; and block-forming towers that produced 19.1-kg blocks. The blocks were vacuum-packaged and aged for 3 mo before being cut into retail-sized chunks for smoking. One 19.1-kg block was segregated for this study and cut into retail-sized samples (approximately $47 \times 60 \times$ $100 \mathrm{~mm}$ ) weighing about $300 \mathrm{~g}$ each. Twelve samples were randomly chosen from this block, 9 of which were assigned to smoking treatment and 3 of which served as a control (not smoked). The 3 control samples were vacuum-packaged and stored at $4^{\circ} \mathrm{C}$. The 9 samples that were assigned to smoking treatment were wrapped in an airtight plastic tote bag and transported to a commercial smokehouse. Upon arrival, the samples were removed from the tote bag and placed inside the smokehouse chamber, where they were exposed to natural vaporous smoke at $20^{\circ} \mathrm{C}$ for approximately $6 \mathrm{~h}$. After smoking, the samples were vacuum packaged and transported with the control samples to the University of Vermont by overnight express mail in an insulated shipping container containing ice packs.

Upon receipt (2 d after smoking), 3 smoked and 3 control samples were analyzed for chemical composition. The remaining samples were stored at $5^{\circ} \mathrm{C}$ until analysis at $4 \mathrm{wk}$ and $10 \mathrm{wk}$ after smoking. In preparation for the analyses, each cheese sample was sliced into 5 sections that represented 5 different depths $(0-2$, $2-4,4-6,6-8$, and $8-10 \mathrm{~mm})$ from the 2 largest $(\sim 60$ $\times 100 \mathrm{~mm})$ opposite surfaces, as illustrated in Figure 1. Sections were cut using a wire cutting device, and each pair of sections with comparable depth from the 2 opposite surfaces was combined and grated in a blender to give a composite sample for that depth. Thus, 5 composite samples were prepared that represented 5 different depths from the 2 largest cheese surfaces: 0 to 2,2 to 4,4 to 6,6 to 8 , and 8 to $10 \mathrm{~mm}$. The composite samples from the 3 smoked and 3 control cheese samples were analyzed immediately (i.e., d 2 after smoking) in duplicate for moisture, $\mathrm{pH}, \mathrm{L}(+)$ and $\mathrm{D}(-)$ lactate, total Ca, and water-soluble Ca (WSC). A second and third set of 3 smoked cheese samples were sectioned and analyzed similarly at 4 wk and 10 wk after smoking, respectively. Moisture content was determined by drying in a forced-draft oven (Thermo Electron, Model $130 \mathrm{DM}$, Winchester, VA) at $100^{\circ} \mathrm{C}$ for $24 \mathrm{~h}$. Watersoluble Ca was determined using the extraction method described by Metzger et al. (2001). Total Ca and Na in cheese samples and $\mathrm{Ca}$ in water-soluble extracts were determined by inductively coupled plasma atomic emission spectrometry. Salt $(\mathrm{NaCl})$ was calculated by multiplying $\mathrm{Na}$ content by a factor of 2.54 . Cheese $\mathrm{pH}$ was measured using a Beckman $50 \mathrm{pH} /$ ISE Meter (Beckman Instruments Inc., Fullerton, CA) by direct immersion of a ROSS combination spear-tip pH electrode (Orion Research Inc., Beverly, MA) into a finely ground sample at ambient temperature. Determination of $\mathrm{L}(+), \mathrm{D}(-)$, and total lactate was by a colorimetric method (test kit no. 11112821035; Boehringer Mannheim/R-Biopharm AG, Darmstadt, Germany). Lactose in control cheese samples was determined by a colorimetric method (test kit no. 10176 303035). Salt, $\mathrm{L}(+)$ and total lactate, and WSC contents were expressed as concentrations 


\section{$(45 \times 60 \times 100 \mathrm{~mm})$}

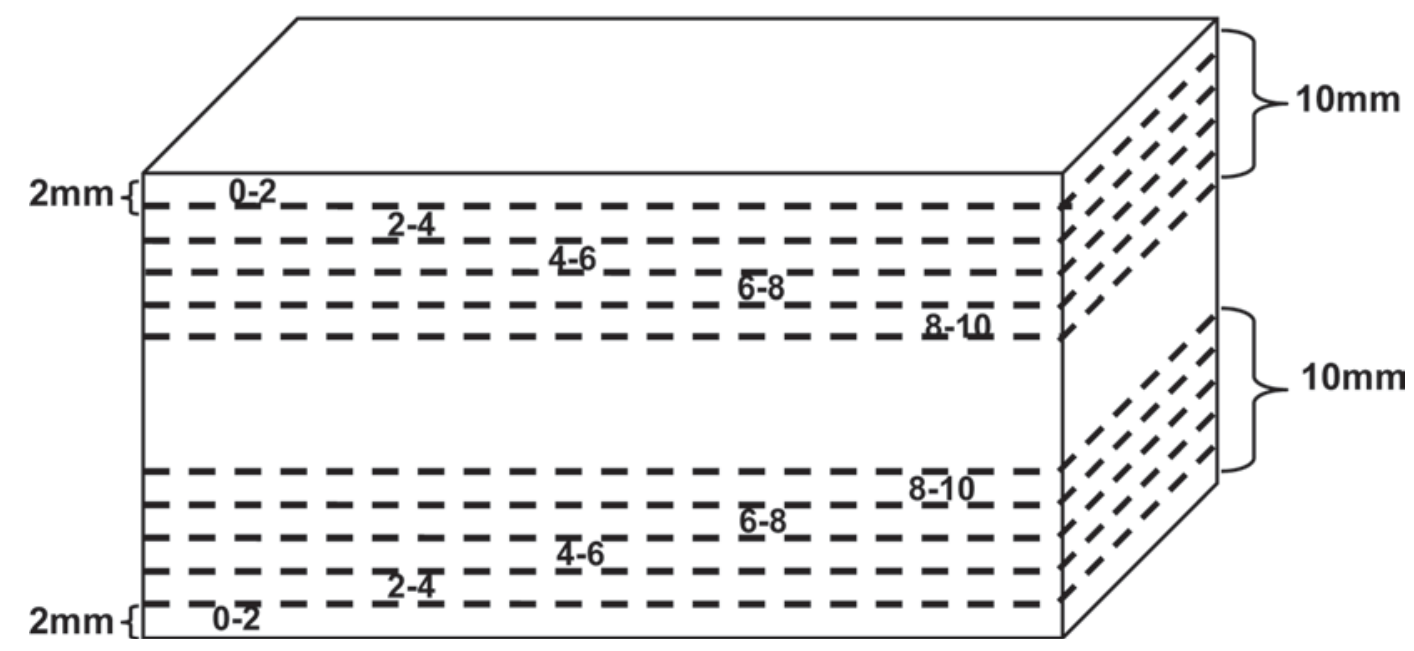

Figure 1. Schematic representation of sectioning plan used to prepare cheese samples for chemical analyses.

on a moisture basis and referred to as salt-in-moisture, $\mathrm{L}(+)$ lactate-in-moisture, total lactate-in-moisture, and WSC-in-moisture.

Compositional data obtained at 2 d after smoking were analyzed statistically using a repeated measures ANOVA with 2 within-subjects variables to determine the effects of smoking treatment, depth from the cheese surface, and the interaction effect of depth $\times$ treatment (SPSS version 15.0, Chicago, IL).

\section{RESULTS AND DISCUSSION}

Surface dehydration often occurs in foods that are subjected to natural vaporous smoking. However, the literature relating to smoked cheeses is very limited and contains conflicting results, presumably because different investigators have used different smoking techniques. For example, Washam et al. (1985) reported that crystals that were present at the surface of smoked processed Swiss cheese were caused by surface dehydration during smoking. In contrast, Shakeel-Ur-Rehman et al. (2003) reported that smoking caused significant increases in the moisture contents of Cheddar cheese samples that had been aged for various lengths of time before they were smoked. In the present study, Cheddar cheese samples were exposed to vaporous smoke for about $6 \mathrm{~h}$ at $20^{\circ} \mathrm{C}$ in a commercial smokehouse and then analyzed for moisture content $2 \mathrm{~d}$ later. The smoking treatment had a significant effect on moisture content (Table 1). In addition, the effect of depth from the cheese surface and the interaction effect of depth $\times$ treatment on moisture content were also significant (Table 1). The data presented in Figure 2A reveal that control cheeses had average moisture contents of about $39.5 \%$, which did not vary with depth from the surface. In contrast, the smoked cheeses had lower average moisture contents than control cheeses at all depths from the surface, and they displayed a steep gradient of decreasing moisture from the interior of the cheese to the surface, hence the significant effects of treatment, depth, and depth $\times$ treatment (Table 1 ). Consequently, the surfaces of the smoked cheeses were about 5.5\% lower in moisture content than the control cheeses on average, confirming that substantial moisture was lost from the cheese surface during smoking.

Loss of moisture during smoking should cause soluble constituents to become more concentrated within the water phase of the cheese in direct relation to moisture loss. Therefore, in the present study, soluble components should have become most concentrated in the water phase at the surface of the smoked cheeses where dehydration was most severe (Figure 2A). Consistent with this, the statistical analysis revealed that levels of $\mathrm{L}(+)$ lactate-in-moisture were significantly affected by smoking treatment, depth from the cheese surface, and the interaction effect of depth $\times$ treatment (Table $1)$. The data presented in Figure $2 \mathrm{~B}$ indicate that average $\mathrm{L}(+)$ lactate-in-moisture levels were higher in smoked cheeses than in control cheeses at all depths. Furthermore, the smoked cheeses displayed a gradient of increasing $\mathrm{L}(+)$ lactate-in-moisture from the cheese interior to the surface. It is worth noting, however, that in contrast to the highly nonlinear moisture gradient (Figure $2 \mathrm{~A}$ ), the gradient of $\mathrm{L}(+)$ lactate-in-moisture was nearly linear (Figure 2B), which suggests that mobile lactate ions had already partially equilibrated 


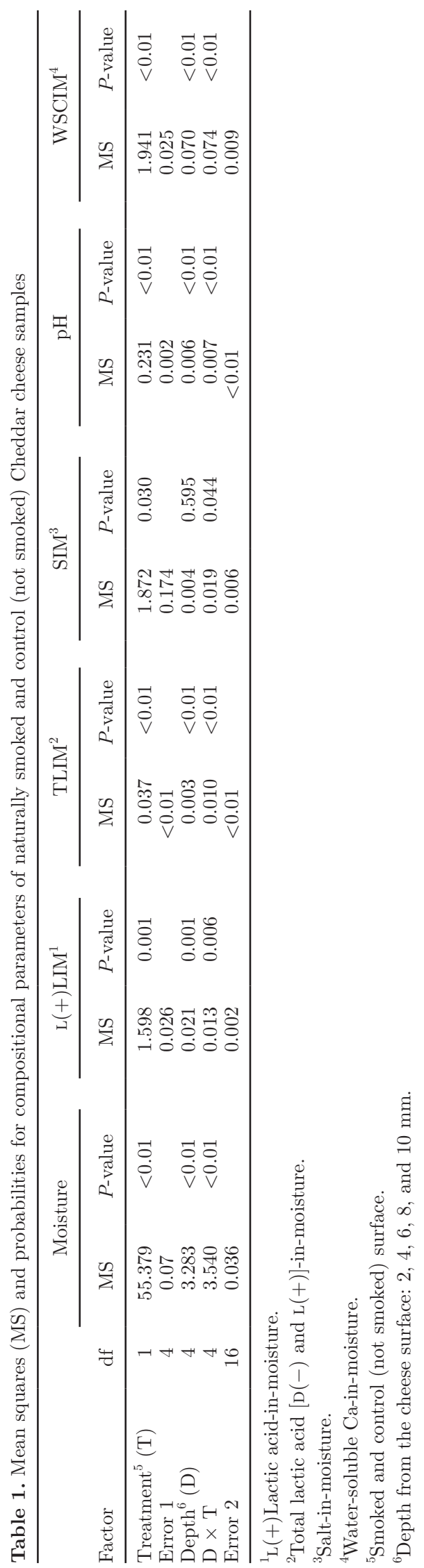

during the $2 \mathrm{~d}$ that elapsed between the smokehouse treatment, when the concentration gradients were established, and the chemical analyses of the cheeses.

Similar results were obtained for total lactate [i.e., the sum of $\mathrm{L}(+)$ and $\mathrm{D}(-)$ lactate], as indicated by the data in Table 1 and Figure 2C. For both smoked and control cheese samples, $\mathrm{D}(-)$ lactate accounted for $6 \%$ of total lactate content, therefore the smoking treatment did not affect racemization of $\mathrm{L}(+)$ to $\mathrm{D}(-)$ lactate by nonstarter bacteria.

Smoking treatment and the interaction of depth $\times$ treatment significantly affected salt-in-moisture levels (Table 1). Average salt-in-moisture levels were higher in smoked cheeses than in control cheeses at all depths (Figure 2D). However, in contrast to the comparatively large gradients of $\mathrm{L}(+)$ lactate (Figure $2 \mathrm{~B}$ ) and total lactate (Figure 2C) evident in smoked cheeses, the saltin-moisture gradient was very small (Figure 2D). Evidently, the smaller size and greater mobility of sodium ions enabled them to equilibrate more rapidly than the more bulky and slower moving lactate ions during the $2 \mathrm{~d}$ that elapsed between smokehouse treatment and chemical analyses. Consequently, salt-in-moisture gradients were virtually eliminated after $2 \mathrm{~d}$ of storage, whereas lactate-in-moisture gradients were still prominent.

The $\mathrm{pH}$ values of cheese samples were significantly affected by smoking treatment, depth from the cheese surface, and the interaction effect of depth $\times$ treatment (Table 1). The data presented in Figure $1 \mathrm{E}$ indicate that the average $\mathrm{pH}$ of the control cheeses was about 4.85 , which is atypically low for Cheddar cheese but is consistent with the high moisture contents (ca. 39.5\%), and therefore high total lactate-in-moisture contents, of these commercially produced cheeses. The $\mathrm{pH}$ of smoked cheeses was even lower than that of control cheeses, and the smoked cheeses displayed a steep gradient of decreasing $\mathrm{pH}$ from cheese interior to surface. Consequently, the surface of the smoked cheeses averaged more than $0.15 \mathrm{pH}$ units lower than control cheeses (Figure 2E). Fermentation of residual lactose during smoking triggered by the high ambient temperature $\left(20^{\circ} \mathrm{C}\right)$ was ruled out as cause of $\mathrm{pH}$ decline because the control cheeses contained no residual lactose (data not shown). This was not surprising because the cheeses were aged for 3 mo before being smoked, which provided ample time for complete fermentation of residual lactose. Gradients of lactate-in-moisture (Figure $2 \mathrm{C}$ ) may have contributed to the $\mathrm{pH}$ gradients in the smoked cheeses. However, it is likely that the precipitous decline in $\mathrm{pH}$ at the cheese surface was caused primarily by the absorption of volatile acids that were present in the smoke. The absorption of smoke-derived acidic compounds at the surface of meat products has 
been shown to cause protein denaturation and hydrolysis and color formation (Gilbert and Knowles, 1975).

Decreases in cheese $\mathrm{pH}$ and the establishment of $\mathrm{pH}$ gradients should favor shifts in Ca distribution from the casein-associated to the soluble state (Guinee et al., 2000; Ge et al., 2002, Swearingen et al., 2004; Agarwal et al., 2006). Therefore, in the present study, soluble Ca should have become most concentrated in the water phase at the surface of the smoked cheeses where the decrease in $\mathrm{pH}$ was the greatest (Figure $2 \mathrm{E}$ ). Consistent with this, the statistical analysis revealed that WSC-inmoisture concentrations were significantly affected by smoking treatment, depth from the cheese surface, and the interaction effect of depth $\times$ treatment (Table 1 ). The data presented in Figure $2 \mathrm{~F}$ indicate that average WSC-in-moisture levels were higher in smoked cheeses
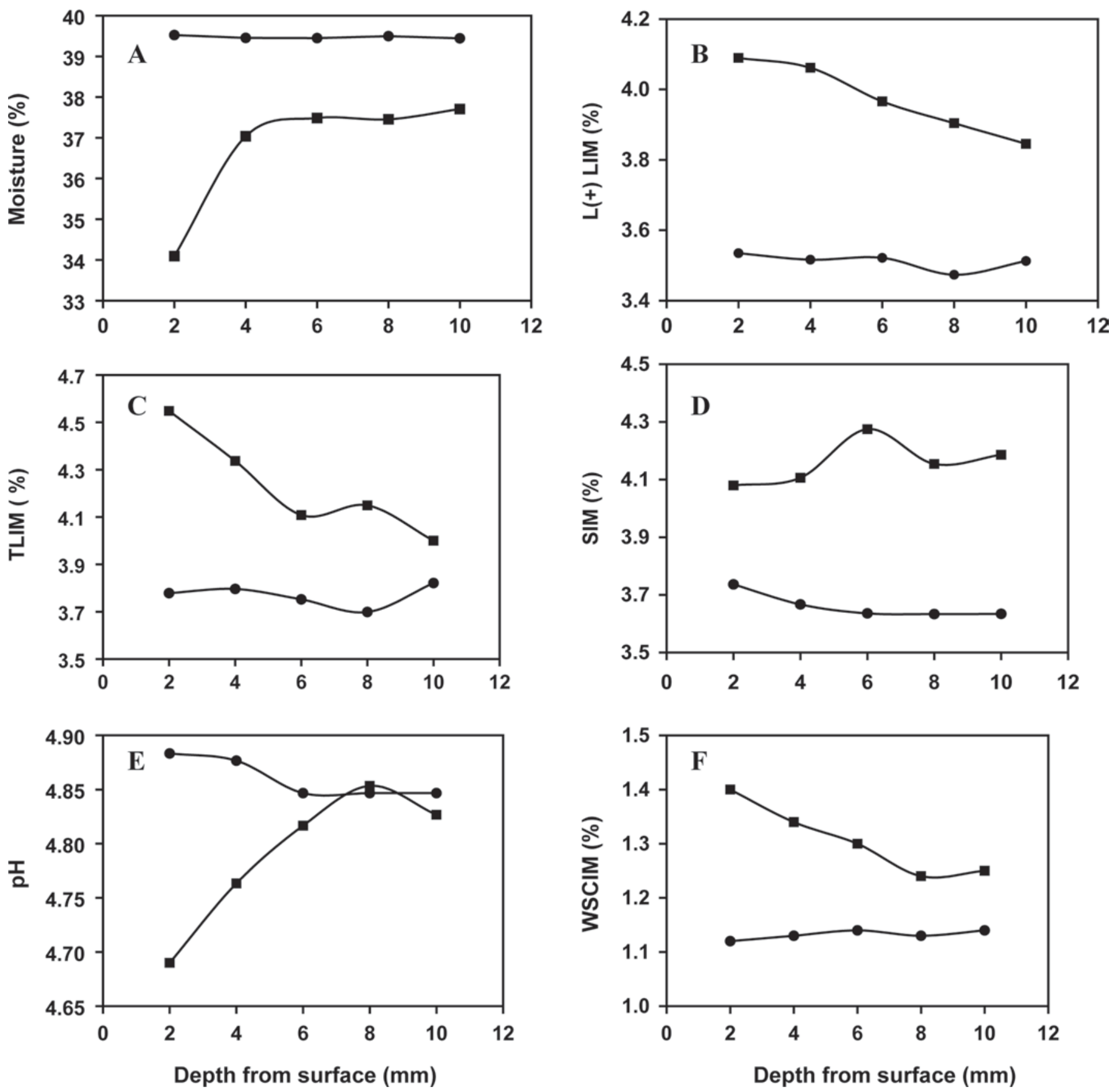

Figure 2. Average chemical composition of smoked $(\mathbf{\square} ; 2 \mathrm{~d}$ after smoking) and control $(\mathbf{\bullet}$; not smoked $)$ cheese samples: $\mathrm{L}(+)$ LIM $=\mathrm{L}(+)$ lactate-in-moisture; TLIM = total lactic acid $[\mathrm{D}(-)$ and $\mathrm{L}(+)]$-in-moisture; SIM $=$ salt-in-moisture; WSCIM $=$ water-soluble Ca-in-moisture. 

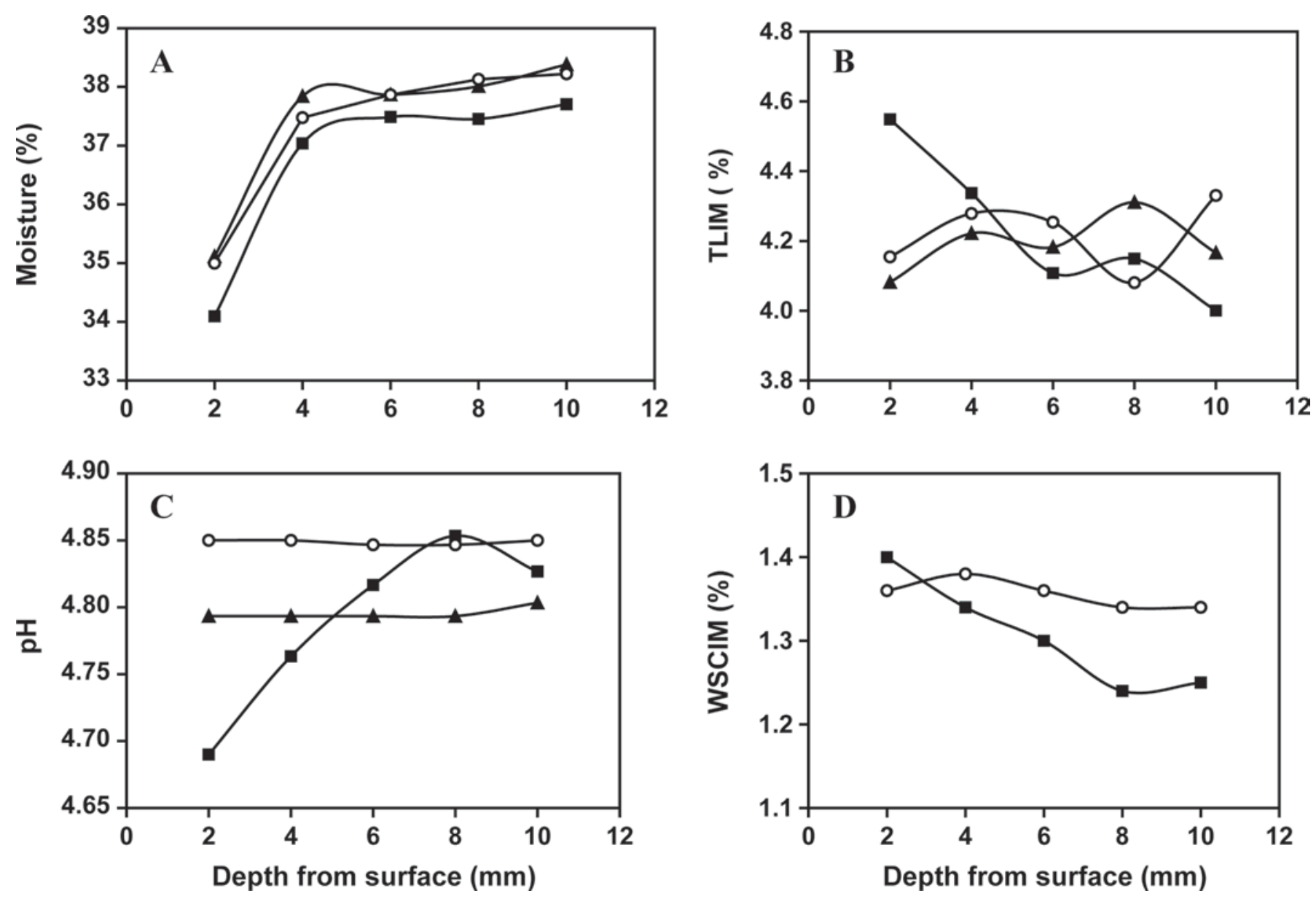

Figure 3. Average chemical composition of smoked cheese samples at $2 \mathrm{~d}$ after smoking lactic acid $[\mathrm{D}(-)$ and $\mathrm{L}(+)]$-in-moisture; WSCIM $=$ water-soluble Ca-in-moisture.

than in control cheeses at all depths. Furthermore, the smoked cheeses displayed a gradient of increasing WSC-in-moisture content from cheese interior to surface. A strong negative correlation $\left(\mathrm{R}^{2}=-0.95\right)$ occurred between the WSC-in-moisture levels (Figure $2 \mathrm{~F}$ ) and $\mathrm{pH}$ values (Figure 2E) of the smoked cheeses at different depths from the surface, which agreed with the expected effect of $\mathrm{pH}$ on $\mathrm{Ca}$ distribution.

Chemical analyses of the smoked cheeses were repeated after 4 and $10 \mathrm{wk}$ of storage at $5^{\circ} \mathrm{C}$. Gradients of moisture (Figure $3 \mathrm{~A}$ ) persisted in the smoked cheese after 4 and 10 wk of refrigerated storage. In contrast, gradients of total lactate-in-moisture (Figure 3B) and $\mathrm{pH}$ (Figure 3C) had disappeared by 4 wk after smoking as lactate and hydrogen ion concentrations equilibrated throughout the cheese. Data for WSC-in-moisture were only available for wk 10 after smoking, at which point equilibration had been reached and the gradient was no longer present (Figure 3D). In Mozzarella cheese, calcium distribution has been shown to respond to changes in cheese $\mathrm{pH}$ within $24 \mathrm{~h}$ (Kindstedt et al., 2001; Ge et al., 2002). In the present study, therefore, it is likely that calcium distribution in the smoked cheeses equilibrated at about the same rate as the $\mathrm{pH}$, in direct response to $\mathrm{pH}$ shifts.

In summary, Cheddar cheese samples in the present study were substantially dehydrated during smoking, which created steep gradients of moisture from the cheese interior to the surface, as well as gradients of lactate-in-moisture within the cheese. This resulted in elevated concentrations of lactate in the water phase of the cheese, and especially at the cheese surface. Soluble Ca also was elevated in the cheese, and especially at the cheese surface, during smoking because of dehydration and the establishment of $\mathrm{pH}$ gradients from the cheese interior to the surface. Thus, smoking resulted in higher concentrations of both $\mathrm{Ca}$ and lactate ions within the water phase at the cheese surface immediately after smoking, which would have the effect of elevating the potential for surface crystallization of Ca lactate. Dur- 
ing storage, gradients of soluble $\mathrm{Ca}$ and lactate ions were reduced as equilibration took place within the smoked cheeses, but concentrations of $\mathrm{Ca}$ and lactate remained elevated because of the lower moisture content and lower initial $\mathrm{pH}$ of the smoked cheeses. Thus, these results suggest that natural vaporous smoking under the conditions used in this study tends to predispose Cheddar cheese to a higher potential for calcium lactate crystallization by inducing higher concentrations of $\mathrm{Ca}$ and lactate ions in the water phase of the cheese.

From the standpoint of reducing the risk of crystallization in smoked Cheddar cheese, these results suggest that care should be taken to avoid selecting cheeses for smoking that are inherently high in lactate or soluble calcium, or both. For example, very high moisture cheeses, such as the control cheeses in the present study (Figure 2), are probably less suitable for smoking because they tend to be low in $\mathrm{pH}$ because of their higher residual lactose and lower protein content/ buffering capacity. Abnormally low Cheddar cheese $\mathrm{pH}$ and the resultant increase in soluble calcium content are known to be risk factors for calcium lactate crystal defects (Swearingen et al., 2004). Natural smoking of such cheese exacerbates the problem by concentrating lactate and soluble Ca levels through dehydration and by shifting the $\mathrm{pH}$ further downwards, driving the concentration of soluble $\mathrm{Ca}$ even higher and thereby rendering the cheese more prone to crystal formation.

\section{ACKNOWLEDGMENTS}

The financial support of New England Dairy Promotion Board, the Vermont Dairy Promotion Council, and USDA Hatch Project VT-H01305 is gratefully acknowledged.

\section{REFERENCES}

Agarwal, S., J. R. Powers, B. G. Swanson, S. Chen, and S. Clark. 2006. Cheese $\mathrm{pH}$, protein concentration, and formation of calcium lactate crystals. J. Dairy Sci. 89:4144-4155.

Anastasio, A., R. Mercogliano, L. Vollano, T. Pepe, and M. L. Cortesi. 2004. Levels of benzo[a]pyrene (BaP) in "Mozzarella di Bufala Campana" cheese smoked according to different procedures. J. Agric. Food Chem. 52:4452-4455.

Bosset, J. O., B. Jeangros, T. Berger, U. Buetikofer, M. Collomb, R. Gauch, P. Lavanchy, J. Scehovic, J. Troxler, and R. Sieber.
1999. Comparison of Swiss hard cheese Gruyere-type produced in highland and lowland. Rev. Suisse d'Agric. 31:17-22.

Ge, Q., M. Almena-Aliste, and P. S. Kindstedt. 2002. Reversibility of $\mathrm{pH}$-induced changes in the calcium distribution and melting characteristics of Mozzarella cheese. Aust. J. Dairy Technol. $57: 3-9$.

Gilbert, J., and M. E. Knowles. 1975. The chemistry of smoked foods: A review. J. Food Technol. 10:245-261.

Guillén, M. D., G. Palencia, P. Sopelana, and M. L. Ibargoitia. 2007. Occurrence of polycyclic aromatic hydrocarbons in artisanal Palmero cheese smoked with two types of vegetable matter. J. Dairy Sci. 90:2717-2725.

Guillén, M. D., and P. Sopelana. 2004. Occurrence of polycyclic aromatic hydrocarbons in smoked cheese. J. Dairy Sci. 87:556564.

Guinee, T. P., D. Harrington, M. O. Corcoran, E. O. Mulholland, and C. Mullins. 2000. The composition and functional properties of commercial Mozzarella, Cheddar and analogue pizza cheeses. Int. J. Dairy Technol. 53:51-56.

Kindstedt, P. S., A. Zielinski, M. Almena-Aliste, and C. Ge. 2001. A post-manufacture method to evaluate the effect of $\mathrm{pH}$ on Mozzarella cheese characteristics. Aust. J. Dairy Technol. 56:202-207.

Lustre, A. O., and P. Issenberg. 1969. Volatile components of hardwood sawdust smoke. J. Agric. Food Chem. 17:1387-1393.

Metzger, L. E., D. M. Barbano, and P. S. Kindstedt. 2001. Effect of milk preacidification on low fat Mozzarella cheese: III. Post-melt chewiness and whiteness. J. Dairy Sci. 84:1357-1366.

Rajbhandari, P., and P. S. Kindstedt. 2005a. Compositional factors associated with calcium lactate crystallization in smoked Cheddar cheese. J. Dairy Sci. 88:3737-3744.

Rajbhandari, P., and P. S. Kindstedt. 2005b. Development and application of image analysis to quantify calcium lactate crystals on the surface of smoked Cheddar cheese. J. Dairy Sci. 88:41574164 .

Riha, W. E., and W. L. Wendorff. 1993. Evaluation of color in smoked cheese by sensory and objective methods. J. Dairy Sci. 76:14911497.

Riha, W. E., W. L. Wendorff, and S. Rank. 1992. Benzo(a)pyrene content of smoked and smoke-flavored cheese products sold in Wisconsin. J. Food Prot. 55:636-638.

Ruiter, A. 1979. Color of smoked foods. Food Technol. 33:54-63.

Shakeel-Ur-Rehman, N. Y. Farkye, and M. A. Drake. 2003. The effect of application of cold natural smoke on the ripening of Cheddar cheese. J. Dairy Sci. 86:1910-1917.

Suchanová, M., J. Hajslová, M. Tomaniová, V. Kocourek, and L. Babicka. 2008. Polycyclic aromatic hydrocarbons in smoked cheese. J. Sci. Food Agric. 88:1307-1317.

Swearingen, P. A., D. E. Adams, and T. L. Lensmire. 2004. Factors affecting calcium lactate and liquid expulsion defects in Cheddar cheese. J. Dairy Sci. 87:574-582.

U.S. Dairy Export Council. 2007. U.S. specialty cheeses. USDEC News. June: 5-10.

Washam, C. J., T. J. Kerr, V. J. Hurst, and W. E. Rigsby. 1985. A scanning electron microscopy study of crystalline structures on commercial cheese. Pages 749-761 in Developments in Industrial Microbiology. Vol. 26. Society for Industrial Microbiology, Arlington, VA. 